\section{Future of fillings}

As amalgam continues to be phased out, there are a number of new materials coming to the fore. One standout product that is quickly becoming a favourite with practitioners is Fill-Up! dual curing bulk fill composite manufactured by COLTENE.

Faster than the conventional increment technique and capable of providing deep, perfect results in a single step with minimal shrinkage and excellent marginal adaption, Fill-Up! ticks all the boxes; and all at a reasonable price that dentists and patients alike can afford.

It comes in a universal shade that matches A2-A3 on the VITA shade guide to blend in well with the surrounding teeth, so aesthetics are improved too.

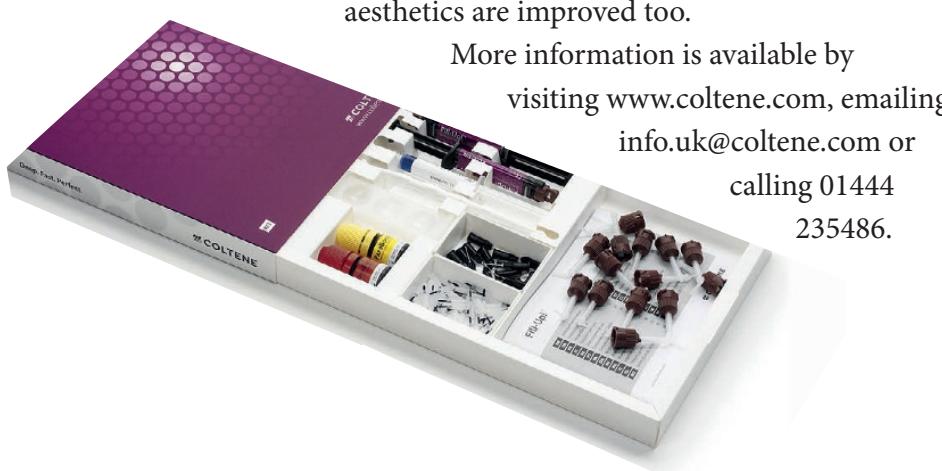

\section{Pleasing precision with ultrasound technology}

Dental implantology is widely accepted as a predictable, highly effective solution to tooth loss and as patients have developed a greater expectation of their dental implants, it is up to those in the profession to ensure optimum results.

With the Piezomed system from W\&H, practitioners can operate with accuracy through innovative ultrasound technology.

Allowing practitioners to cut through bone with precision, the Piezomed minimises the risk of injuring the surrounding soft tissue, whilst offering better visibility in the working area during surgery. This allows for more efficient operating conditions for the practitioner, and an enhanced treatment experience for the patient.

Automatically able to detect the instrument upon insertion, the Piezomed also offers a continuous supply of coolant from the tip of the instrument to the operating site, effectively decreasing the amount of bone-damaging heat generated. This promotes stable osseointegration for accelerated soft and hard tissue healing.

To find out more, visit www.wh.com/en_uk, call 01727874990 or email office.uk@wh.com.

\section{Vegan-friendly treatment}

Veganism is growing in popularity, but patients might not be aware of the possible oral health implications of this plant-based diet, which can cause dental erosion and decay.

Leading oral healthcare specialist Curaprox says dentists should remind patients to follow effective at-home oral care routines with high quality, vegan-friendly adjuncts supplied by the company.

This includes the CS 5460 ultra soft manual toothbrush, which has been innovatively designed with fine CUREN filaments to facilitate efficient, but gentle tooth brushing.

When combined with the Black Is White range, Curaprox delivers the complete dental cleaning solution, so that patients can ensure their teeth always look and feel their best.

For more information, call 01480 862084, email info@ curaprox.co.uk or visit www.curaprox.co.uk.

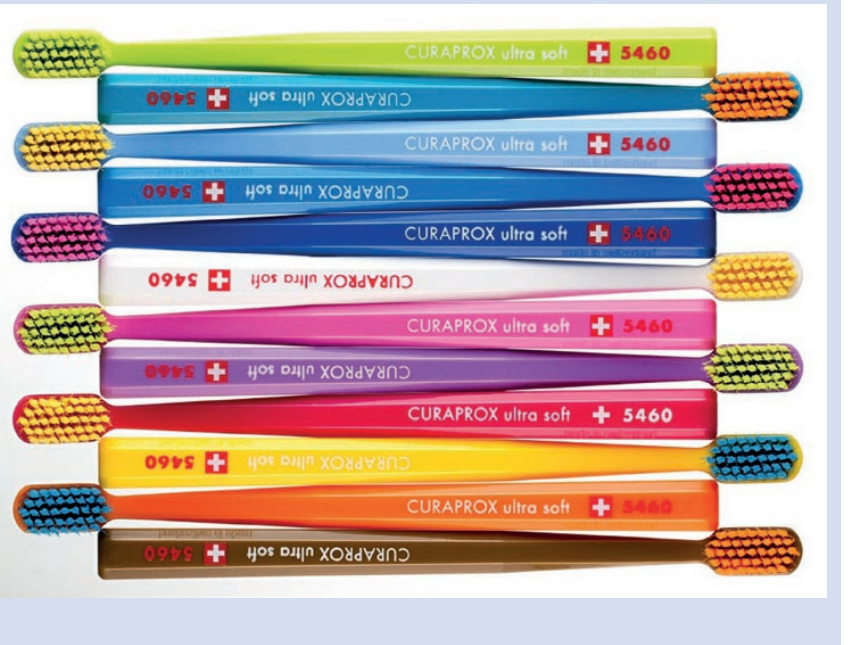

\section{Avoiding nickel allergies}

Nickel allergies can cause lasting distress for patients if they are exposed to the metal during dental treatment. So how can you be sure that the restorations you use are nickel free?

CosTech Dental Laboratory is here to help. Not only are all restorations fabricated by CosTech completely nickel free, but the laboratory is also DAMAS accredited and offers a number of benefits including personal pick up and strict time management - meaning you'll always get your restoration when you need it.

For more information about CosTech Dental Laboratory, please visit www.costech.co.uk or call 01474320076.
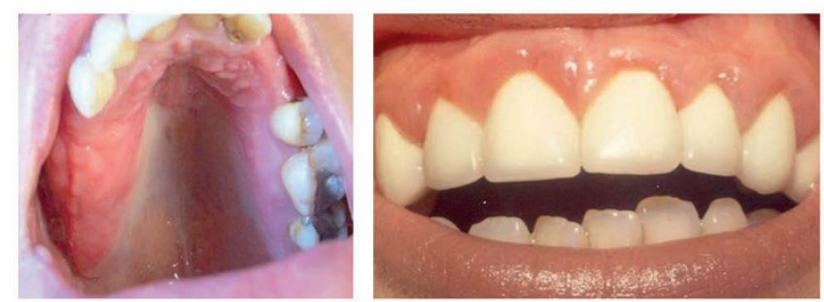